\title{
Product dependability testing of polymer composite materials
}

\author{
A. Čapka \& L. Fojtl \& S. Rusnákova \& M. Žaludek \\ Department of Production Engineering, Faculty of Technology, Tomas Bata University in Zlin, Czech \\ Republic
}

\begin{abstract}
This research paper deals with a proposal of the most appropriate methodology for dependability testing of products used in transport industry. Dependability is a global concept that includes terms of availability, reliability, durability, maintainability, supportability, etc. An important part of dependability is to find limit states of studied object, which are for PCM characterized by fiber cracking and delamination. Based on these specific failures, building-block approach (BBA), which allows a systematic approach is often used for evaluation of composite constructions. Dependability evaluation consists of analysis and tests. Tests are always very time-consuming and expensive, because dependability is a property of objects with the strong stochastic character and therefore it is necessary to perform numerous measurements. Conversely, the analysis itself without verification may not achieve the desired results. For every test, it is necessary to develop the test plan and determine whether it is possible to use shortened or accelerated test.
\end{abstract}

\section{INTRODUCTION}

Polymer composites are materials, which increasingly replacing conventional construction and building materials such as steel, aluminum, concrete, etc. The replacement of traditional materials occurs because PCM can have more optimal properties than traditional materials. With the creation of a priority request to reduce the weight of motor vehicles, which is related to necessity reduce of the emission amount, PCM became basic material to fulfil this requirement.

One of the major problems of contemporary world is the quality of production and services. Countries with high quality of production and services have simultaneously a high level of population life quality. One of the most important properties belonging to the notion of quality is dependability (Malkin 2005).

Scientific approach to dependability began with introduction of electronics to aerospace and defense industry around the middle of last century (Vasiljev 1988). Dependability is very elaborately standardized in specific national and international standards. Crucial role in the dependability standardization plays International Electrotechnical Commission.

Consistent terminology is the foundation of every scientific discipline. In PCM there is no Czech terminology standard. There is standard ČSN EN 472 ISI Plastics - dictionary, in which a few terms from the field of PCM are located, but they are only in foreign languages (English, French and German). In the standard ČSN EN 4408-001 - Aerospace series Technical drawing and in the other standards there are only a few terms from PCM.

\subsection{Basic terms and definitions of PCM}

Composite material - construction material composed of two or more chemically and physically different components (phases), which are not mutually dissolved and have identifiable phase interface; composite always consists of a matrix and reinforcement, where synergistic effect is always achieved.

Fiber reinforced composite - construction material with long-fiber reinforcements, where the length of fiber is much greater than its diameter; reinforcement have much higher strength than matrix.

Laminate - composite manufactured from two or more layers containing reinforcing fibers oriented in one or more directions.

Matrix - basic component (phase) of the composite, which is used to store reinforcement, transfer load on the reinforcement, ensure the product shape, and protect reinforcement against damage; matrix has usually lower strength than the reinforcement.

Polymeric composite material (PCM) - composite, which have the matrix (or also fibers) made of polymer.

Resin - polymer used as matrix that is by mean of hardener polymerized (cured). 
Fiber - natural or synthetic product, finite or infinite length, which is an essential element of fabric or other textile structures.

Lamina - element or set of elements in a certain level, the layer may consist of several sublayers.

Reinforcement - reinforcing component of the composite, which in fiber composites transfers most of applied load.

\subsection{Basic terms and definitions of dependability}

Standardization of technical terminology in dependability is very well elaborated, therefore individual terms are not described (except for durability).

Durability - ability of an object to fulfill a required function under given application conditions and maintenance until achievement of limit state.

\subsection{Classification of composite materials}

Figure 1 shows basic classification of composites due to their material constitution.

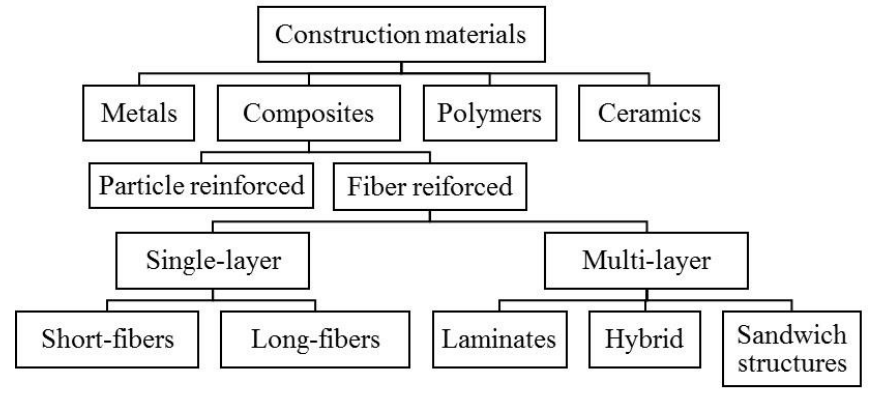

Figure 1. Classification of composite materials

Composites can be divided according to different aspects, e.g. by matrix:

- Metal matrix

- Carbon matrix

- Ceramic matrix

- Polymer matrix

also by manufacturing technology:

- Hand lay-up

- Partially mechanized

- Fully mechanized and automated

or by types of individual components, form of reinforcement, structure and number of components.

\section{DEPENDABILITY OF PCM PRODUCTS}

\subsection{Dependability classification}

Function of any technical system can be characterized its quality. The term quality means the totality of properties that define ability of the system to fulfill specific objectives. Dependability (Figure 2) is one of the quality characteristics of technical object.

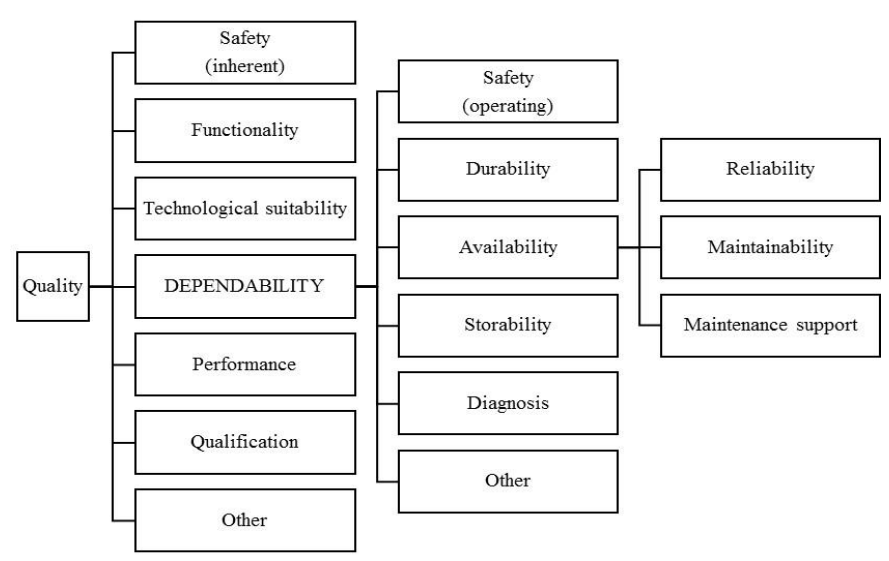

Figure 2. Dependability classification

\subsection{Building-block approach (BBA)}

BBA method allows to shorten and mainly cheapen tests of PCM construction. A numerous experiments have to be performed, if individual tests are carried out for constructions itself. However, these tests are very time-consuming and expensive. Furthermore, it is also impossible to perform only construction analysis using computational methods. In practice, a combination of analysis and tests is conducted. Following figure (Figure 3 ) depicts structure of BBA.

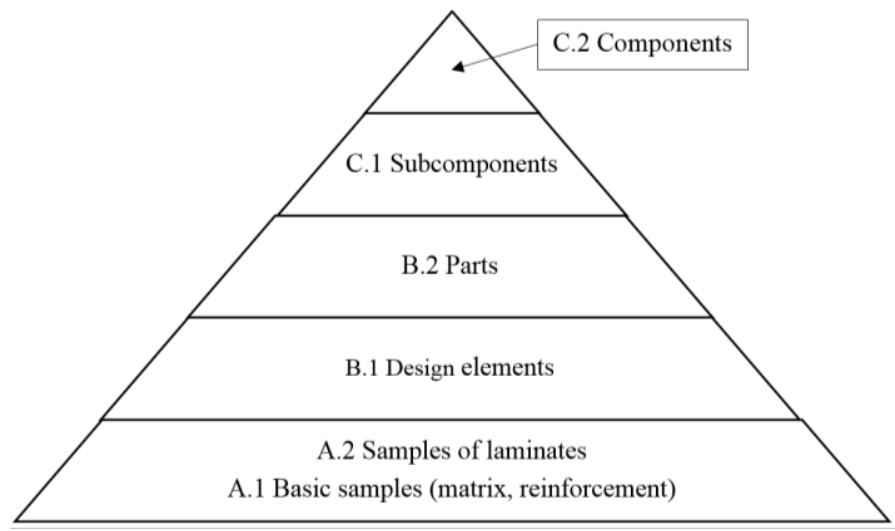

Figure 3. Structure of BBA method

BBA method works analytically and experimentally at three basic levels:

- Fist level (A):

A.1 Basic material samples; (matrix, reinforcement; data of strength and modulus)

A.2 Lamina and laminate samples (data of strength and modulus)

- Second level (B):

B.1 Design elements

B.2 Components of critical zones of construction, e. q. stiffeners, beams; (local static and fatigue loads, 
data of strength and stiffness, local damage, environmental impact)

- Third level (C):

C.1 Subcomponents (subassemblies as complete wing spar)

C.2 Components - real constructions or parts, e. q. wing; (complex tests, verification, tests until failure during both static and fatigue stresses).

\subsection{PCM limit states}

During the lifetime, every product goes through different stages. In this specific period, product properties (stages) are changed (technical, economical, ecological stages, etc.). Limit state (LS) occurs when the state variable reaches the limit value (Jones 1999). Achievement of the limit state has always probabilistic nature (probability of error-free operation).

The most frequent limit states in PCM products (sorted according to severity):

- LS related to failure of part cohesion (cohesive failure of reinforcement and matrix, cracks in matrix, fracture of the reinforcing fibers, delamination)

- LS related to the part deformation (local buckling of shell without fiber damage and delamination)

- LS related to damage of part surface (UV radiation, humidity, operating fluids, etc.).

\section{ANALYSIS AND DEPENDABILITY TESTING OF PCM PRODUCTS}

During all stages of product life, it is necessary to deal with product dependability. Therefore, it is necessary to develop a program of product dependability to ensure this parameter to be an essential characteristic of quality.

\subsection{Dependability analysis (analytical- modeling method)}

The specific information required for a decision about the system characteristics are obtained, examined and evaluated during dependability analysis (Trivedi 1992, Gurtjahr 2000). These analyses are conducted on models and are standardized. In practice, following methods are for example used:

- Failure mode and effects analysis (FMEA), or extended FMECA to indicate critical analysis

- Graphical methods (event and fault tree, logical block diagram, etc.)

- Marks methods
- Simulation methods (Monte Carlo method, SBRA, method of artificial intelligence, etc.) tic:

Dependability analysis has two basic characteris-

- Interactive (interdependence of various stages, utilization of previously obtained empirical data, analyzes correction based on real-time operation)

- Iterative (repetition, accuracy improvement until achievement of set goal)

Dependability analysis is performed in four basic stages (as well as in all other fields):

- Functional and technical analysis (data collection, preliminary analysis)

- Qualitative analysis (objectives determination, scope, division of the system, application of one above mentioned methods, creation of dependability model, failure definitions)

- Quantitative analysis (calculation of dependability indicators, sensitivity analysis)

- Synthesis (assessment of achieved dependability level, conclusion).

\subsection{Dependability tests}

Dependability tests (Figure 4) are used for experimental determination or verification of dependability indicators. The aim of tests is to verify values of parameter distribution of corresponding quantity. These tests can be classified into following groups:

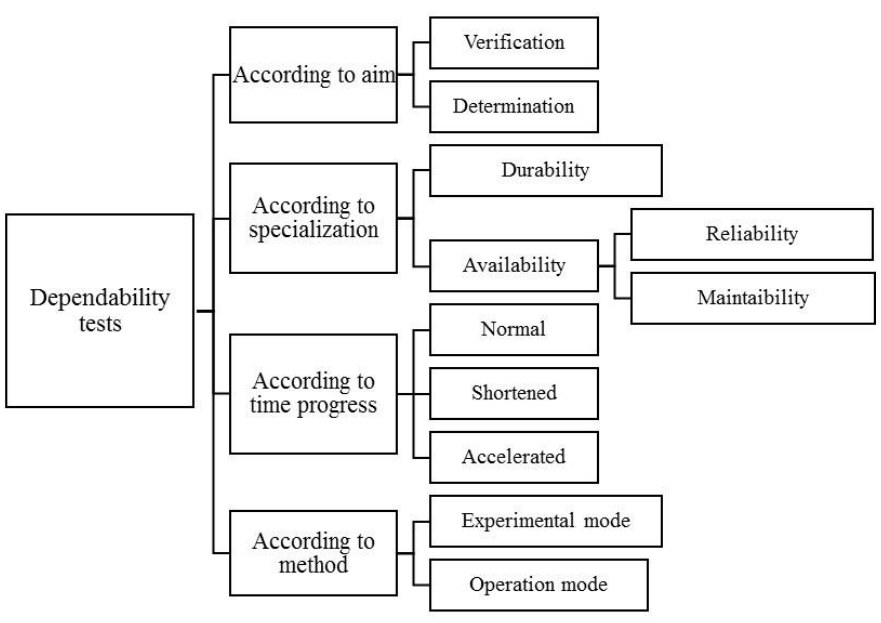

Figure 4. Classification of dependability tests

Furthermore, test plan for every dependability test have to be prepared. This plan defines methodology of progress and test end mode. Test plans are divided according to obtained data set to tests with results, which consist of: 
- Complete set ( $\mathrm{n}$ - number of specimens, U damaged specimen is not replaced or repaired after failure and is removed from the test, $\tau_{0}-$ length of test)

- Set limited by number of failures $(r-$ plan $)$

- Set is limited by time $(\mathrm{t}-$ plan)

- Progressively limited set (miscellaneous plan)

Every test plan includes:

- Number of specimens

- Information, if specimen will be removed, replaced by new, or repaired after failure

- Method of test end (test duration or description at which failure will the test be stopped).

During the durability test of parts and subcomponents, it is time and financial advantageous to use shortened tests. These shortened tests last until the first failure and serves mainly to estimate the mean time to failure (estimation of distribution parameter to failure).

For products, where long-term trouble-free operation in a matter of decades is expected, the accelerated tests are used. There are two basic method of accelerated tests:

- accelerated by greater use (especially for products that are not in continuous service)

- accelerated by overload (load higher than under normal operating conditions)

The crucial dependability test of PCM products is a durability test. Especially in Aerospace Engineering with respect to safety, it is necessary to perform an extensive set of durability tests, which are given by aviation regulations.

The result of durability test is creation of damage curve, which ends by one of limit state (Harris 2003). Damage curve of PCM contains of three basic phases:

I. phase: cracks in matrix, or/and failure of reinforcing fibers

II. phase: cracks linking, failures at interlaminar interface and delamination

III. phase: delamination grow and final failure

\section{CONCLUSION}

Dependability of PCM constructions in contrast to for example steel structures are not fully investigated. It is among other things related to the fact that the mechanism of composite fatigue damage is different from metals. Methods for evaluation of dependability and also durability of PCM is still evolving. Almost totally unexplored area is dependability of PCM constructions and parts used in the field of civil transport vehicles (automobiles, rails buses, ships).

Moreover, for evaluation of PCM constructions dependability, it is necessary to take into account the modern theories of dependability, modern knowledge from materials science, technologies, mathematical modeling and statistics. It is necessary to solve dependability in all stages of product lifecycle and apply the knowledge from aerospace industry into transport industry PCM products.

\section{ACKNOWLEDGEMENT:}

This study was supported by the internal grant of TBU in Zlin No. IGA/FT/2015/001 funded from the resources of specific university research.

\section{REFERENCES}

Ehrenstein, G. W. 2009. Polymerní kompozitní materiály. Praha: Scientia.

Gutjahr W. J. 2000. Software dependability evaluation based on Markov usage models. Performance Evaluation 40 (4). 199-222.

Harris, B. 2003. Fatigue in composites: science and technology of the fatigue response of fibre-reinforced plastics. Cambridge: Woodhead Publishing.

Jones, R. M. 1999. Mechanics of composite materials. Philadelphia: Taylor.

Malkin, V.S. 2005. Osnovy teorii naděžnosti $i$ diagnostiki. Toljati: TGU.

D3878-07. 2013. Standard Terminology for Composite Material. ASTM International.

Trivedi K. S. Muppala J. K., Woolet S. P., Haverkort B. R. 1992. Composite performance and dependability analysis. Performance Evaluation 14 (3-4). 197-215.

Vasiljev, V.V. 1988. Konstrukciji iz kompozicionnych materialov. Moscow: Mašinostrojenije. 